\title{
A NEGOCIAÇÃO COLETIVA COMO FERRRAMENTA REGULAMENTADORA DE NORMA ABERTA: O TELETRABALHO E A LEI 12551/2011
}

The collective negotiation and regulatory standard open: the teleworking and the Law $12551 / 2011$

\section{Denise Pires Fincato}

\section{Michelle Dias Bublitz}

\author{
Pontifícia Universidade Católica - PUC/RS - Porto Alegre - Rio Grande do Sul - Brasil
}

Resumo: A sociedade não é e nunca foi estática, muito ao contrário, está em constante mutação, e como tal, sofre o impacto, nesses processos de mudança, das chamadas novas tecnologias. Identifica-se um novo paradigma de sociedade: a sociedade da informação, que baseia suas trocas e a métrica do poder no domínio de num bem precioso, o conhecimento. O espaço virtual, cada vez mais, vai se tornando a grande biblioteca da humanidade, no qual estão inseridos a vida social, política e econômica, e, porque não, também a vida laboral da pessoa humana. Todas essas transformações foram inseridas nas relações de trabalho que não mais apresentam as características de tempo, espaço e organização que antes apresentavam, onde a energia e o esforço físico do trabalho humano eram os responsáveis pelo desenvolvimento da economia. A tradicional relação de trabalho e de emprego, aos poucos cede espaço a novas relações contratuais que não exigem a presença física do trabalhador. O teletrabalho revela uma mudança de paradigma manifestada em uma nova modalidade laboral, novos métodos de trabalho e também em um novo ambiente de trabalho, descentralizado dos centros de produção e centrado na produção, armazenamento e transformação do conhecimento e da informação com o uso maciço das novas tecnologias como ferramenta de trabalho. Assim sendo, este estudo tem por objetivo analisar o teletrabalho como nova modalidade de trabalho, notoriamente no contexto brasileiro, apreciando se a novel legislação possui o condão de evitar ou resolver os conflitos resultantes e apresentando, caso necessárias, alternativas, principalmente à luz do direito comparado europeu e da experiência negocial coletiva brasileira.

Palavras-chave: Teletrabalho. Regulamentação. Negociação Coletiva.

\begin{abstract}
The society is not and has never been static, on the contrary, is constantly changing, and as such, must observe the impact these processes of change, the so-called new technologies. Identifies a new paradigm of society: the information society, which based its power exchanges and the metric in the domain of a precious commodity, knowledge. The virtual space increasingly is becoming the great library of humanity, in which are inserted into the social, political and economic, and why not, also the working life of the human person. All these changes were inserted into the working relationships that no longer have the characteristics of time, space and organization that had before, where the energy and physical exertion of human labor were responsible for the development of the economy. The traditional employment relationship and employment, gradually gives way to new contractual relationships that do not require the physical presence of the worker. Teleworking reveals a paradigm shift manifested in a new way of work, new working methods and also a new work environment, decentralized production centers and focused on production, storage and processing of knowledge and information with the massive use of new technologies as a tool. Therefore, this study aims to examine telework as a new form of work, notably in the Brazilian context, enjoying the novel legislation has the power to prevent or resolve conflicts arising and presenting, if necessary, alternative, particularly in light of the right Europe compared.
\end{abstract}

keywords: Teleworking. Regulation. Collective negotiation. 


\section{INTRODUÇÃO}

A partir da última década do século $X X$ e, principalmente, na primeira década do século XXI, acentuou-se o fenômeno da globalização, notoriamente em razão da revolução tecnológico-informacional, que permitiu o surgimento de novas profissões e a reformulação das antigas, assim como acarretou significativa mudança nas relações de trabalho, permitindo relacionamentos laborais transnacionais sem deslocamentos físicos, inclusive.

Observa-se, portanto, que o trabalho modificou-se ao longo do tempo, na medida em que as tecnologias de informação e de comunicação tornaram-se um elemento indissociável do desenvolvimento da atividade econômica, constituindo-se em fator cada vez mais importante na organização e estruturação das sociedades modernas.

Assim sendo, a realidade revela uma mudança de paradigma em que as tradicionais formas de prestação de serviços aos poucos vão cedendo espaço às novas relações contratuais, as quais não exigem a presença física do trabalhador.

Ressalta-se que justamente os progressos tecnológicos foram os propulsores da possibilidade de criação de novas formas de trabalho, em especial o teletrabalho, objeto central da presente pesquisa, propulsor da continuidade do processo econômico de descentralização produtiva e que anda de mãos dadas com a globalização e flexibilização das relações de emprego.

O teletrabalho, diante de suas características conceituais e estruturais altamente polêmicas, ainda gera debates sobre seu surgimento, estruturação, organização, manutenção, aplicação, extinção ou regulamentação no cenário brasileiro, bem como europeu, e atualmente fomenta relevantes pesquisas.

Fato é, que o teletrabalho é modalidade de trabalho (especialmente trabalho subordinado, dito emprego, foco de interesse deste estudo) já utilizado em vários países, principalmente na Europa e América do Norte, há décadas e em larga escala. No Brasil, face a própria condição de país em desenvolvimento e, também em razão de suas dimensões territoriais (COCco, 2000), a consolidação desta modalidade de trabalho tem sido paulatina e, observa-se, muito mais concretizável em determinados segmentos econômicos e profissões, do que em outros. 


\section{MUNDO DO TRABALHO: GLOBALIZAÇÃO E TELETRABALHO}

Em face do fenômeno da globalização, a mudança do paradigma produtivo passa a constituir um ponto importante para análise do atual estado político, econômico e social da humanidade.

Baseado em uma produção e consumo em massa, de modo centralizado (cocco, 2000), e contínuo, o sistema taylorista/fordista, em ascensão no pós-Primeira Guerra Mundial, lançou desafios para o cenário produtivo da época. A partir daqui, por mais vezes, a produção deixa de ser centralizada, já que se passa a observar aspectos de mão de obra e custos de produção em geral. Este mercado entrou em crise em razão da crescente competição internacional, propulsada pelos avanços tecnológicos (ROCHA, 2004). Com este cenário, a quebra das barreiras nacionais se tornou inevitável, dinamizando o processo de globalização (MELO FILHO, 2000).

Boaventura de Souza Santos afirma que, nas últimas três décadas, as interações transnacionais tomaram maior intensidade, amplitude e profundidade otimizando o fenômeno multifacetado da globalização (SANTOS, 2005). ${ }^{1}$

Diante deste novo momento, onde a globalização e as tecnologias de comunicação se confundem, pode-se dizer que a sociedade está vivendo uma nova mudança no seu sistema de produção. Este novo modelo de atuação pode ser denominado como "Revolução Tecnológica" ou também, "Revolução Informacional". $\mathrm{O}$ atual modelo é caracterizado pelo papel central ocupado pelo conhecimento e pela informação, assim como pela aplicação deles para a geração de mais conhecimento, em um círculo de retroalimentação (ROCHA, 2004). Seguindo a análise do desenvolvimento dos modos de produção, Castells afirma que "a tecnologia da informação é para esta revolução o que as novas fontes de energia foram para as revoluções industriais sucessivas, do motor a vapor à eletricidade, aos combustíveis fósseis e até mesmo à energia nuclear" (CASTELLS, 2000, p. 50). Acerca das transições tratadas pelo autor, Domenico De Mais complementa, expondo ter ocorrido ao fim da Segunda Guerra Mundial, quando a produção "de bens materiais que caracterizava

Com relação a temática da globalização, sigo o entendimento de FRIEDMAN, Thomas L. O mundo é plano - o mundo globalizado no século XXI. 3.ed. Rio de Janeiro: Objetiva, 2009.

REVISTA DO DIREITO UNISC, SANTA CRUZ DO SUL №. 44 | p.107-135 | SET-DEZ 2014 
a sociedade industrial deu lugar a produção de bens imateriais (serviços, informações, etc) que caracterizam a sociedade pós industrial' (DE MASI, 1999. p. 221).

Castells (2000) pondera, que embora o modo capitalista de produção seja caracterizado por sua expansão contínua, que pretende sempre superar os limites temporais e espaciais, foi apenas no final do século $X X$ que a economia mundial conseguiu tornar-se verdadeiramente global, com base na nova infraestrutura, propiciada pelas tecnologias da informação e comunicação. Ainda, Castells (2000) afirma que a redefinição histórica da relação capital-trabalho foi possibilitada pela capacidade de usufruir de mão de obra em qualquer lugar e a qualquer momento.

Assim sendo, o antigo modelo produtivo deu lugar a um novo sistema, este descentralizado no que se refere aos locais de trabalho e centralizado no sentido de conhecimento, da informação e da comunicação via tecnologia. Os efeitos deste novo modo de produzir há pouco podem ser percebidos, visto o modo gradual como a mudança vem ocorrendo.

Não há dúvida de que, a cada dia, é mais difícil obter uma vaga no mercado formal de emprego. Visto que a alta competitividade para o ingresso e a manutenção no mercado de trabalho são as principais características do mercado atual. 0 fenômeno da globalização, acompanhado da necessidade das empresas para que otimizem a sua atividade produtiva, interfere diretamente para ocorrência deste comportamento do mercado. Em paralelo, o surgimento de novos recursos tecnológicos, que permitem a crescente ampliação da automação, também tem influência os novos parâmetros observados. O desenvolvimento e o uso das tecnologias da informação e comunicação possibilitaram a descentralização do trabalho, e este fato reflete-se no número de pessoas que hoje trabalham a distância, em instituto também conhecido como teletrabalho.

Em um mundo cada vez mais globalizado e sob os impactos do rápido avanço tecnológico, as relações de trabalho estão sofrendo modificações em suas antigas formas de organização, adaptando-se ao surgimento, cada vez mais célere, de novos modos de produção e de novos usos para o potencial humano de trabalho. Estamos diante de um novo tipo de trabalho, oriundo da reorganização do trabalho intelectual e manual. Ainda que não se possa considerar tão somente a reorganização dos processos de trabalho, mas também a integração produtiva nos territórios e nas redes sociais que os desenham. É preciso observar também, os 
comportamentos de consumo (cocco, 1999), bem como os atuais padrões de relacionamento pessoal, através das redes sociais.

$O$ teletrabalho surge então, como uma realidade laboral, que em alguns espaços ainda carece de definição conceitual e regulamentação legislativa satisfatória, mas é propagado como promissor, já que se anuncia sua tendência de gerar novos empregos (ou apenas trabalho?), auxiliar na manutenção dos existentes e regularizar a situação dos trabalhadores que se encontram à margem da lei e de sua proteção.

\section{DEFINIÇÃO DE TELETRABALHO²}

Definir teletrabalho constitui uma difícil tarefa, na medida em que há um sem número de variações terminológicas, e suas flexões conforme o contexto geográfico, temporal e até mesmo científico.

A palavra telecommuting ${ }^{3}$, que originou o vocábulo teletrabalho na língua portuguesa, foi utilizada pelo norte-americano Jack Nilles (1997), na década de 70. Definindo como qualquer atividade profissional que é realizada fora do local tradicional de trabalho, em que alguma das técnicas de telecomunicação é utilizada. O Autor define que o objetivo dessa nova forma de prestação laboral seria "a possibilidade de enviar o trabalho aos trabalhadores, em vez de levar estes ao trabalho" (NILLES, 1998. p. 1-17).

Carmen Algar Jiménez (2007) segue a mesma linha de raciocínio, ao definir de modo teórico o teletrabalho como a modalidade que corresponde com aquela em que o trabalho é realizado fora do local onde o resultado deste é esperado, por meio do uso de ferramentas e/ou tecnologias de comunicação.

Denise Pires Fincato (2003), enfim, afirma que é teletrabalho:

[...] fenômeno moderno (ou nem tanto) a partir do qual alguém presta serviços por meio das ferramentas de comunicação e informação

\footnotetext{
2 No que toca ao estudo do teletrabalho, segue-se o pensamento consolidado no Grupo de Pesquisas "Novas Tecnologias e Relações de Trabalho", sediado na Pontifícia Universidade Católica do Rio Grande do Sul - PUCRS e com registro no Conselho Nacional de Desenvolvimento Científico e Tecnológico - CNPq, coordenado pela Profa . Dra . Denise Pires Fincato, que possui como integrantes advogados trabalhistas e acadêmicos dos mais diversos graus (graduandos, bacharéis, especialistas, mestres e doutores). Trata-se do único grupo de pesquisas com perfil científico-acadêmico que se dedica a estudar o fenômeno do teletrabalho no Brasil.

Commuting é uma palavra que designa a viagem de ida e volta entre o domicílio e o local de trabalho.
} 
(notoriamente internet), distante geograficamente de seu tomador de serviços. A relação poderá ser autônoma ou subordinada [...].

A título de direito comparado, existem países que já definiram juridicamente o teletrabalho, tais como: Itália, Espanha, Portugal e Chile; com forte destaque ao Acordo Marco Europeu sobre Teletrabalho, norteador de iniciativas legislativas europeias e com perfil de norma comunitária.

Inequivocamente, regulamentar o teletrabalho trata-se do cerne da questão. A crescente evolução dos meios informacionais voltados à conectividade e à crescente eficácia da comunicação, inserida no contexto globalizado em que passou supra descrito. Torna-se, a cada dia, mais possível enviar o trabalho e a estrutura de trabalho, mesmo que virtual, ao trabalhador; o que possui seus prós e contras.

De modo geral, o teletrabalho se caracteriza pelo uso das telecomunicações para alterar a geografia do trabalho, segundo a European Commission (2000). Ainda, abrange diversos aspectos, tais como econômico, social, cultural, organizacional, tecnológico, ambiental, legal e outros, e diversos atores, como: organizações, indivíduos, governos, fornecedores de tecnologias de informação, sindicatos e outros.

Destaca-se, a título de nomenclatura, que os autores americanos costumam utilizar o termo telecommuting, enquanto os europeus preferem telework. $\mathrm{O}$ que reflete o foco diverso de atenção que as diferentes definições desenvolvidas até hoje abordam: a localização quando utilizado telecommuting, trabalho fora do local tradicional de trabalho da empresa, e por processo ao utilizar a expressão teleworking, em função do uso de tecnologias de informação e comunicação - TICs ou Tls.

A problemática da tutela do teletrabalho perpassa não apenas pelas questões conceituais, mas também pela falta de entendimento jurídico mínimo sobre a matéria. $\mathrm{O}$ que acaba por manter em aberto questionamentos jus-sociais, que no estágio atual de desenvolvimento do Estado Democrático de Direito, não podem ficar à mercê de soluções esparsas e dissonantes, o que como vem ocorrendo atualmente com a jurisprudência trabalhista brasileira em face da Lei 12551/2011. A falta de um conceito legal minimamente preciso, que o julgador possa utilizar para realizar a subsunção da realidade fática à lei e alcançar os direitos constitucionalmente previstos aos teletrabalhadores, tem criado a verdadeira 
insegurança jurídica, que acaba por impedir o desenvolvimento e a adaptação sócioeconômica do trabalho nacional, alijando milhares de trabalhadores do uso seguro da modalidade contratual do teletrabalho e expondo-os à precarização de suas relações. O olhar oposto também pode ser realizado, no sentido de que a ausência de conteúdo legislativo mínimo, deixa empregadores expostos à incerteza em suas relações com seus empregados. Apesar de utilizar esta possibilidade de nova forma laboral como um imperativo mercadológico, ao empregador, utilizá-la desconhecendo suas obrigações sociais pode ser o naufrágio do empreendimento.

\section{PRINCIPAIS CARACTERÍSTICAS}

O teletrabalho constitui modalidade de trabalho com características próprias (JIMÉNEZ, 2007), dentre as quais: a distância, situação laboral em que teletrabalhador se encontra num ponto geograficamente distinto daquele em que o trabalho é realizado tradicionalmente e/ou entregue, tecnologia, recurso intensivo a meios informáticos e de telecomunicações - redes, equipamentos e aplicações/serviços para suporte e/ou entrega (transferência) de teletrabalho, estruturação, existência de um acordo claro entre os intervenientes (teletrabalhador-empresa e empregadoracliente) que estabeleça e regule as condições laborais e as condições de trabalho, forma organizativa, a partir de casa do trabalhador, em centros de teletrabalho, escritórios satélite, teletrabalho móvel, escritórios partilhados, offshore (teletrabalho transfronteiriço), etc., modalidade, formal ou informal, tempo integral, tempo parcial, em alternância (alguns dias por semana) ou ocasional (FINCATO, 2012)

Então, a condição para haver teletrabalho, portanto, é a necessária separação do trabalhador e do ambiente tradicional de prestação laboral, além do uso das tecnologias da informação e comunicação como ferramenta de trabalho.

\section{TIPOLOGIA}

De acordo com o critério adotado, várias são as modalidades de teletrabalho.

A partir desta premissa, o teletrabalho pode ser classificado através do critério comunicativo, isto é, pelo grau de conexão existente entre empregador e empregado 
ou entre tomador de serviços e trabalhador ${ }^{4}$. Desta forma, nas modalidades a seguir descritas:

Teletrabalho off line, também chamado de desconectado ou unpluged, caracterizado quando o trabalhador realiza sua atividade sem manter vinculação telemática alguma com o empregador. O computador, se existir, não é utilizado como forma de comunicação, mas como mera ferramenta de trabalho e processamento de informação.

Teletrabalho online, também chamado de conectado, é a modalidade que revela o típico teletrabalho, já que é através dela, que trabalhador e empregador se comunicam continuamente, em total sincronia e de modo bidirecional. Ação que é facilitada pelas tecnologias de comunicação e informação.

Já a modalidade one way line é a variação do modelo online. Nela a comunicação se dá de forma unimodal, como por exemplo, com a utilização de pagers convencionais, que não permitem interatividade simultânea (FINCATO, 2009) ou com uma das vias, entrega ou devolução do trabalho, de forma não tecnológicoinformacional.

No que tange à classificação, pode-se observar e categorizar o teletrabalho também de acordo com o local de onde ele é prestado. Sendo que, suas principais modalidades são: telecottages, telecentros ainda, teletrabalho nômade e, por último, em domicílio. Veja-se:

O teletrabalho em telecottages é aquele que é realizado em zonas rurais ou regiões de menor nível de escolaridade e preparo para o trabalho. Quase se confunde com os telecentros, não fosse o particular de sua localização. Via de regra, são utilizadas instalações públicas, como salões de lgrejas, escolas ou até mesmo edificações em fazendas, observando sempre que todos devem estar devidamente adequados e informatizados. Com sucesso, experiências importantes nesta modalidade de teletrabalho são realizadas em países como Inglaterra, Irlanda, Suécia (norte), Noruega, Finlândia, Dinamarca, França e Alemanha (FINCATO, 2012).

O telecentro, por sua vez, é uma forma de organização das atividades em um espaço devidamente preparado para o desempenho do teletrabalho. Pinho Pedreira (200) afirma que "os telecentros são locais da empresa, porém situados fora da sua

\footnotetext{
4 O teletrabalho admite modalidade autônoma ou subordinada, por isto a sequencia aparentemente antagônica. Dependerá da analise do caso concreto a definição da existência de vinculo empregatício, ou não.
} 
sede central'. Em verdade, os telecentros podem ser locais pertencentes à empresa ou não, uma vez que são divididos em Centro Satélite e Centro Local de Teleserviço. O Centro Satélite é um edifício, ou parte de um, que pertence à empresa, separado de sua sede central, mas que com ela está em permanente comunicação telemática, não se confundindo com uma filial da mesma. Tais centros estão situados em pontos geograficamente estratégicos e estão abertos a todos os teletrabalhadores das circunvizinhanças (independentemente de sua função ou cargo), vinculados empregaticiamente à empresa. Já o Centro Local de Teleserviço, também chamado de Telecentro Compartilhado ou Telecentro Comunitário, é um lugar pertencente a um grupo, que disponibiliza esse espaço, via aluguel, para várias empresas onde coexistem trabalhadores, estes vinculados a vários empregadores ou até mesmo a profissionais independentes. Ainda, este local pode pertencer ao Estado, onde os funcionários de muitas empresas compartilham o mesmo endereço profissional. Neste caso, o Estado atua na estruturação física destes locais, sem estabelecer qualquer vínculo algum com os empregados ou com as empresa.

Já o teletrabalho nômade, também denominado móvel ou itinerante, é caracterizado pela ausência de determinação quanto ao local de onde o teletrabalhdor estará prestando serviços (FINCATO, 2012). O empregado realiza suas atividades de qualquer lugar, desde que disponha de equipamentos telemáticos que Ihe permitam realizar o seu trabalho. Pode-se afirmar que esta é a máxima expressão do teletrabalho, já que o sujeito trabalha de onde quer ou precisa. Nesta modalidade, o teletrabalhador, nessa modalidade, pode executar suas tarefas de casa, na sede do cliente ou mesmo no trânsito, por exemplo.

Através do teletrabalho em domicílio (PEDREIRA, 2000), o trabalhador realiza suas atividades em seu próprio domicílio ou em ambiente familiar, com o auxílio de mecanismos telemáticos ${ }^{5}$. Aqui, o teletrabalhador instala, em um local específico de sua residência, com estrutura própria ou cedida pela empresa, uma pequena estação de trabalho com acesso aos meios de comunicação necessários para a realização das suas funções, tais como: telefone, fax, computador, internet, etc. $O$ teletrabalhador em domicílio pode estar em sua casa durante todo o período (regime

Telemática é a utilização da informação através do uso combinado de computador e meios de comunicação.

REVISTA DO DIREITO UNISC, SANTA CRUZ DO SUL

№. 44 | p.107-135 | SET-DEZ 2014 
puro) ou fracioná-lo (regime híbrido), realizando, por exemplo, meio turno na empresa e meio turno em sua residência, ou ainda, alguns dias da semana na empresa e outros em casa. O diferencial é que qualquer um dos regimes adotados alterará a estrutura física da empresa que o adotou, já que ao invés de inúmeros gabinetes e postos de trabalho individuais, espaços de uso rotativo, plural, democrático, impessoais e funcionais passarão a compor o layout do ambiente de trabalho. Ainda, no que toca à empresa, o teletrabalho em domicílio (principalmente nas modalidades off line ou one way line) reduz sensivelmente o número de ausências ao trabalho, principalmente por enfermidade do trabalhador ou de seus parentes próximos. Para o trabalhador, tal modalidade contribui para a redução de seus custos pessoais, como: combustível, alimentação e vestuário. Permite ainda, que o trabalhador não se exponha aos riscos urbanos (acidentes, assaltos, etc), retirando-o também do trânsito das grandes cidades (fato gerador de atrasos). Entretanto, os gastos com energia elétrica, calefação/climatização, telefonia, material de expediente (folhas, tinta, etc), dentre outros, devem fazer parte dos encargos das empresas, mas, pelo que se percebe através da realidade fática é que estes acabam sendo repassados ao trabalhador, como ônus.

No campo normativo brasileiro, o teletrabalhador em domicílio equipara-se ao trabalhador em domicílio tradicional, regulamentado pelo artigo $6^{\circ}$ da Consolidação das Leis Trabalhistas.

Os tipos de teletrabalho retro referidos podem ainda, dar-se de acordo com uma ou outra modalidade, dependendo da estrutura que disponham as partes (empresa e empregado) e da natureza da atividade laboral. Sinale-se, todavia, que a tônica do teletrabalho é justamente o uso dos meios de telecomunicação como mediadores da distância e que sua ausência permite a confusão do teletrabalho com o trabalho em domicílio. Importante ressaltar, que por ser o teletrabalho uma modalidade flexível, poderá haver a simultaneidade de espaços de trabalho, sendo possível que o teletrabalhador intercale suas atividades entre o seu domicílio e o telecentro, a empresa ou ainda, entre a empresa e qualquer lugar em que haja a possibilidade da execução da atividade utilizando-se dos meios telemáticos.

Dentre as modalidades supra citadas, destaca-se, para fins deste estudo, 0 teletrabalho no domicílio, o qual se constitui a maneira mais comum de teletrabalhar. 


\section{Vantagens e desvantagens}

Como todo o resultado oriundo de transformações sociais, o teletrabalho também nos permite colher vantagens e desvantagens quanto a sua utilização.

Dentre as vantagens, se encontram as principais questões de interesse direto do empregador, como: redução de custos com estrutura física, simplificação da fiscalização do trabalho, aumento de produtividade, área geográfica de atuação mais ampla, dentre outras. Algumas das vantagens são de interesse direto do empregado, tais como: menores custos de alimentação, transporte e vestuário, mais tempo para atender clientes, maiores oportunidades para pessoas com restrições de tempo e locomoção, relacionamento mais estreito com clientes em comunidades específicas, maior facilidade em atender múltiplas empresas (por parte de especialistas altamente qualificados), equilíbrio de interesses pessoais e familiares incidentais e também o acesso ao trabalho de um contingente humano que, hoje em dia, enfrenta dificuldade em obter emprego formal, atuando assim, como um meio hábil de contribuição para a diminuição da desigualdade de oportunidades, como é o caso dos trabalhadores com deficiência (BRASIL, 2000)

No mais, as vantagens podem se travestir de desvantagens quando, por exemplo, o teletrabalho trouxer diminuição do tempo livre, isolamento social, redução da distinção da vida profissional e da vida particular e menores possibilidades de ascensão profissional (WINTER, 2005). Sendo um dos pontos negativos do teletrabalho o risco de quebra de privacidade. Há o que cuidar nesse aspecto, porque existe 0 risco de se atentar contra as liberdades individuais e o direito de privacidade, garantidos a todas as pessoas (FRANCO FILHO, 1998).

A modalidade de teletrabalho impõe mudanças não só no aspecto econômico, jurídico e social, mas também através do ponto de vista cultural, na medida em que o fenômeno da globalização, que está a aproximar os povos e a eliminar barreiras, também atinge o teletrabalho. Sendo fundamental a busca pelos instrumentos necessários para adaptar as empresas e os trabalhadores a essa irreversível realidade.

Fácil, portanto, chegar à conclusão de que para bem interpretar as relações de trabalho contemporâneas é necessário compreender a liquidez da sociedade 
atual, em que a volatilidade das relações é a tônica e a vida em conjunto (familiar, laboral, política, etc) perde importância, consistência e estabilidade.

\section{REGULAMENTAÇÃO LEGAL}

\subsection{União Européia}

A União Européia (antiga Comunidade Econômica Européia) constitui paradgima singular no cenário do Direito Internacional, com vivência legitimamente comunitária, sua estrutura abarca, por exemplo, um Parlamento ${ }^{6}$ e, ainda, diversas outras estruturas, que estudam, normatizam e orientam as posturas dos países integrantes da comunidade nos mais variados temas.

Em razão disto, a chamada Comissão Européia $^{7}$ convocou os parceiros europeus para debater e ajustar condutas comuns acerca do teletrabalho, reconhecendo-o como realidade inconteste e preocupante à União Européia. Deste encontro, em 2002, resulta o Acordo Marco Europeu sobre Teletrabalho, cuja aplicação nos países membros é recomendada, harmonizando ali as referências negociadas e as contidas à legislação nacional respectiva.

No entanto, apesar do crescente aumento no uso desta nova forma de prestação laboral, o teletrabalho não tem regulamentação específica e minuciosa na maioria dos países. Como visto, na Europa há o Marco Europeu, que é o norte dos textos normativos dos países que o compõem. Como pode ser visto através do artigo 13 do Estatuto dos Trabalhadores da Espanha (alterado pela reforma de 2012 - Real Decreto-ley 3/2012, de 10 de fevereiro, com "medidas urgentes para la reforma del mercado laboral') ${ }^{8}$ :

${ }^{6}$ Bastante didática é a explicação sobre a estrutura e função do Parlamento Europeu, disposta no sítio oficial de internet: <http://europa.eu/about-eu/institutions-bodies/europeanparliament/index_pt.htm>.

7 A Comissão Europeia é uma das principais instituições da UE. Para além de representar e defender os interesses da UE no seu conjunto, a Comissão prepara os projectos de legislação europeia e assegura a execução das políticas e dos fundos da UE. In: <http://europa.eu/about-eu/institutionsbodies/european-commission/index_pt.htm>

8 Em livre versão: Redação artigo 13 do Estatuto dos Trabalhadores, aprovado pelo Real Decreto Legislativo 1/1995, de 24 de março é a seguinte: Artigo 13. Teletrabalho. 1. Será considerado o teletrabalho em que a prestação de atividade de trabalho ocorre predominantemente na casa do trabalhador ou ao local escolhido livremente por ele, uma forma alternativa de encarar o desenvolvimento no local de trabalho da empresa . 2. O acordo para estabelecer o teletrabalho será formalizada por escrito. Se o acordo for estabelecido no contrato inicial, se mais tarde, vamos 
Artículo 13. Trabajo a distancia.

1. Tendrá la consideración de trabajo a distancia aquél en que la prestación de la actividad laboral se realice de manera preponderante en el domicilio del trabajador o en el lugar libremente elegido por éste, de modo alternativo a su desarrollo presencial en el centro de trabajo de la empresa.

2. El acuerdo por el que se establezca el trabajo a distancia se formalizará por escrito. Tanto si el acuerdo se estableciera en el contrato inicial como si fuera posterior, le serán de aplicación las reglas contenidas en el artículo 8.3 de esta Ley para la copia básica del contrato de trabajo.

3. Los trabajadores a distancia tendrán los mismos derechos que los que prestan sus servicios en el centro de trabajo de la empresa, salvo aquéllos que sean inherentes a la realización de la prestación laboral en el mismo de manera presencial. En especial, el trabajador a distancia tendrá derecho a percibir, como mínimo, la retribución total establecida conforme a su grupo profesional y funciones.

El empresario deberá establecer los medios necesarios para asegurar el acceso efectivo de estos trabajadores a la formación profesional continua, a fin de favorecer su promoción profesional. Asimismo, a fin de posibilitar la movilidad y promoción, deberá informar a los trabajadores a distancia de la existencia de puestos de trabajo vacantes para su desarrollo presencial en sus centros de trabajo.

4. Los trabajadores a distancia tienen derecho a una adecuada protección en materia de seguridad y salud resultando de aplicación, en todo caso, lo establecido en la Ley 31/1995, de 8 de noviembre, de Prevención de Riesgos Laborales, y su normativa de desarrollo.

5. Los trabajadores a distancia podrán ejercer los derechos de representación colectiva conforme a lo previsto en la presente Ley. A estos efectos dichos trabajadores deberán estar adscritos a un centro de trabajo concreto de la empresa. ${ }^{9}$

Ainda, a título de exemplificação, o texto do Código de Trabalho Português, em 2003 foi também modificado, seguindo os moldes do Acordo Marco Europeu e assumindo a atual feição, ora transcrita, após nova reforma em 2009:

Artigo 165.

Noção de teletrabalho

aplicar as regras contidas no artigo 8.3 da presente lei para a cópia básica do contrato. 3. Os teletrabalhadores têm os mesmos direitos que aqueles que prestam serviços no local de trabalho da empresa, exceto aqueles que são inerentes ao trabalho de fornecer o mesmo em pessoa. Em particular, o trabalhador remoto terá direito a, pelo menos, a compensação total prevista no seu grupo profissional e funções. O empregador deve estabelecer os meios necessários para assegurar o efetivo acesso desses trabalhadores à formação profissional contínua, a fim de promover seu desenvolvimento de carreira. Além disso, para aumentar a mobilidade e promoção, você deve informar os trabalhadores longe da existência de vagas para o rosto de desenvolvimento em seus locais de trabalho. 4. Os teletrabalhadores têm direito a proteção adequada da segurança e saúde resultante da aplicação, em qualquer caso, as disposições da Lei 31/1995, de 08 de novembro e seus regulamentos de execução. 5. Os teletrabalhadores podem exercer os direitos de representação coletiva, tal como previsto na presente lei para essa finalidade desses trabalhadores deve ser atribuído a um trabalho especial da empresa.

9 Redação segundo Real Decreto-lei 3/2012, de 10 de fevereiro. Disponível em: http://noticias.juridicas.com/base_datos/Laboral/rdleg1-1995.t1.html\#a13 Acesso em: 17/05/2012 
Considera-se teletrabalho a prestação laboral realizada com subordinação jurídica, habitualmente fora da empresa e através do recurso a tecnologias de informação e de comunicação.

Artigo 166.으.

Regime de contrato para prestação subordinada de teletrabalho 1 - Pode exercer a actividade em regime de teletrabalho um trabalhador da empresa ou outro admitido para o efeito, mediante a celebração de contrato para prestação subordinada de teletrabalho.

2 - Verificadas as condições previstas no $\mathrm{n} .-1$ do artigo 195.․ , o trabalhador tem direito a passar a exercer a actividade em regime de teletrabalho, quando este seja compatível com a actividade desempenhada.

3 - O empregador não pode opor-se ao pedido do trabalhador nos termos do número anterior.

4 - O contrato está sujeito a forma escrita e deve conter: a) Identificação, assinaturas e domicílio ou sede das partes; b) Indicação da actividade a prestar pelo trabalhador, com menção expressa do regime de teletrabalho, e correspondente retribuição;

c) Indicação do período normal de trabalho;

d) Se o período previsto para a prestação de trabalho em regime de teletrabalho for inferior à duração previsível do contrato de trabalho, a actividade a exercer após o termo daquele período;

e) Propriedade dos instrumentos de trabalho bem como o responsável pela respectiva instalação e manutenção e pelo pagamento das inerentes despesas de consumo e de utilização;

f) Identificação do estabelecimento ou departamento da empresa em cuja dependência fica o trabalhador, bem como quem este deve contactar no âmbito da prestação de trabalho.

5 - O trabalhador em regime de teletrabalho pode passar a trabalhar no regime dos demais trabalhadores da empresa, a título definitivo ou por período determinado, mediante acordo escrito com o empregador. 6 - A forma escrita é exigida apenas para prova da estipulação do regime de teletrabalho.

7 - Constitui contra-ordenação grave a violação do disposto no n. 3 e constitui contra-ordenação leve a violação do disposto no n.o 4 .

\section{Artigo 167.}

Regime no caso de trabalhador anteriormente vinculado ao empregador 1 - No caso de trabalhador anteriormente vinculado ao empregador, a duração inicial do contrato para prestação subordinada de teletrabalho não pode exceder três anos, ou o prazo estabelecido em instrumento de regulamentação colectiva de trabalho.

2 - Qualquer das partes pode denunciar o contrato referido no número anterior durante os primeiros 30 dias da sua execução.

3 - Cessando o contrato para prestação subordinada de teletrabalho, o trabalhador retoma a prestação de trabalho, nos termos acordados ou nos previstos em instrumento de regulamentação colectiva de trabalho.

4 - Constitui contra-ordenação grave a violação do disposto no número anterior.

\section{Artigo 168. ${ }^{\circ}$}

Instrumentos de trabalho em prestação subordinada de teletrabalho 1 - Na falta de estipulação no contrato, presume-se que os instrumentos de trabalho respeitantes a tecnologias de informação e de comunicação utilizados pelo trabalhador pertencem ao empregador, que deve assegurar as respectivas instalação e manutenção e o pagamento das inerentes despesas.

2 - O trabalhador deve observar as regras de utilização e funcionamento dos instrumentos de trabalho que the forem disponibilizados. 
3 - Salvo acordo em contrário, o trabalhador não pode dar aos instrumentos de trabalho disponibilizados pelo empregador uso diverso do inerente ao cumprimento da sua prestação de trabalho.

\section{Artigo 169.으.}

Igualdade de tratamento de trabalhador em regime de teletrabalho 1 - O trabalhador em regime de teletrabalho tem os mesmos direitos e deveres dos demais trabalhadores, nomeadamente no que se refere a formação e promoção ou carreira profissionais, limites do período normal de trabalho e outras condições de trabalho, segurança e saúde no trabalho e reparação de danos emergentes de acidente de trabalho ou doença profissional.

2 - No âmbito da formação profissional, o empregador deve proporcionar ao trabalhador, em caso de necessidade, formação adequada sobre a utilização de tecnologias de informação e de comunicação inerentes ao exercício da respectiva actividade.

3 - O empregador deve evitar o isolamento do trabalhador, nomeadamente através de contactos regulares com a empresa e os demais trabalhadores.

\section{Artigo 170.}

Privacidade de trabalhador em regime de teletrabalho

1 - O empregador deve respeitar a privacidade do trabalhador e os tempos de descanso e de repouso da família deste, bem como proporcionar-lhe boas condições de trabalho, tanto do ponto de vista físico como psíquico. 2 - Sempre que o teletrabalho seja realizado no domicílio do trabalhador, a visita ao local de trabalho só deve ter por objecto o controlo da actividade laboral, bem como dos instrumentos de trabalho e apenas pode ser efectuada entre as 9 e as 19 horas, com a assistência do trabalhador ou de pessoa por ele designada.

3 - Constitui contra-ordenação grave a violação do disposto neste artigo.

Artigo 171..

Participação e representação colectivas de trabalhador em regime de teletrabalho

1 - O trabalhador em regime de teletrabalho integra o número de trabalhadores da empresa para todos os efeitos relativos a estruturas de representação colectiva, podendo candidatar-se a essas estruturas. 2 - O trabalhador pode utilizar as tecnologias de informação e de comunicação afectas à prestação de trabalho para participar em reunião promovida no local de trabalho por estrutura de representação colectiva dos trabalhadores.

3 - Qualquer estrutura de representação colectiva dos trabalhadores pode utilizar as tecnologias referidas no número anterior para, no exercício da sua actividade, comunicar com o trabalhador em regime de teletrabalho, nomeadamente divulgando informações a que se refere o n. -1 do artigo 465..

4 - Constitui contra-ordenação grave a violação do disposto nos nํ. 2 ou 3.

Destarte, impende estudar o próprio Marco Europeu e seus postulados, o que se fará a seguir.

\subsubsection{Acordo Marco Europeu sobre Teletrabalho ${ }^{10}$}

${ }^{10}$ No tocante ao tema em análise, traduz-se o que diz JIMÉNEZ, Carmen Algar. Teletrabajo. In. EI Derecho Laboral ante el reto de las Nuevas Tecnologias. Madri: Difusión Jurídica y Temas de Actualidade, S.A., 2007. p.13-39

REVISTA DO DIREITO UNISC, SANTA CRUZ DO SUL №. 44 | p.107-135 | SET-DEZ 2014 
O Acordo Marco Europeu sobre Teletrabalho, foi elaborado pela comissão européia convidada pelo Conselho Europeu para tratar do assunto conjuntamente com interlocutores sociais. Ficou estabelecido o marco geral e mínimo sobre esta forma de prestação de trabalho no âmbito europeu. Apesar de ser de adesão voluntária dos Estados membros da Comunidade, o acordo tem sido utilizado por vários países da Europa, assim como por entidades de representação trabalhista e patronal (nas negociações coletivas), como vértice para o estabelecimento das relações de teletrabalho.

O Acordo estabelece a definição e ainda, algumas características particulares desta nova modalidade de organização da prestação de trabalho.

O Teletrabalho, portanto, é definido pelo Acordo Marco Europeu (2002, < http://www.ccoo-servicios.es/archivos/bbva/20110727_acuerdo marco europeo tel etrabajo.pdf) como:

[...] una forma de organización y/o de realización del trabajo, utilizando las tecnologías de la información en el marco de un contrato o de una relación de trabajo, en la cual un trabajo que podría ser realizado igualmente en los locales de la empresa se efectúa fuera de estos locales de forma regular.

Assim, para efeitos didático-normativos, teletrabalhador é a pessoa que exerce atividade laboral nos moldes do parágrafo destacado, ou seja, é aquele que está vinculado a uma empresa, exercendo um trabalho de forma regular, que bem poderia ser exercido nas dependências empresariais, mas não o é. O teletrabalho pode se dar com ou sem subordinação jurídica, apesar de interessar à maioria dos países que primaram em regrar 0 instituto, as relações empregatícias de teletrabalho. Por esta razão, o artigo 4ํ do mencionado Acordo destaca que, naquilo que se refere às condições de emprego, os teletrabalhadores se beneficiam dos mesmos direitos garantidos pela legislação e pelos acordos coletivos aplicáveis aos empregados que laboram nas instalações da empresa. No entanto, tendo em conta as peculiaridades do teletrabalho, disposições específicas podem ser necessárias para indivíduos ou grupos adicionais.

Pelo Acordo, o teletrabalho poderá fazer parte do ajuste inicial da organização do trabalho ou incorporar-se ao contrato de trabalho, via adesão voluntária (exercitada pelo empregado), mais tarde. Em ambos os casos, a configuração da relação de teletrabalho deverá respeitar a vontade individual das partes e, uma vez 
ajustada, deverá ser sucedida pela entrega ao teletrabalhador de toda a informação relevante para execução do trabalho na nova modalidade, tais como: departamento em que está adscrito o trabalhador, seu imediato superior ou outras pessoas a que pode se dirigir, descrição do trabalho a ser realizado, etc. - Isto deve ser especificado de forma escrita. Além do esclarecimento acerca das normas coletivas aplicáveis ao seu regimento laboral. Importante destacar também, que a decisão de passar a teletrabalhar deve ser reversível e instrumentalizada por acordo individual ou coletivo.

Com relação à proteção de dados, o empregador é responsável por tomar medidas adequadas que se impõem, especialmente em relação a softwares, com o objetivo de garantir a proteção dos dados utilizados pelo teletrabalhador para fins profissionais. O empregador deverá informar ao empregado a existência de legislação ou norma coletiva que aborde a questão da proteção de dados, especialmente sobre limitações na utilização das ferramentas informáticas de trabalho. Sendo responsabilidade do teletrabalhador o respeito e cumprimento dessas normas, sob as penas estabelecidas, por consequência.

O empregador, segundo o Marco Europeu, também é obrigado a respeitar a vida privada do empregado e, se decidir adotar algum tipo de sistema de vigilância para o ambiente de trabalho, deverá cuidar para que seja proporcional ao objetivo demandado, o qual deve obedecer ao estabelecido na Diretiva 90/270, relativa às câmeras de vigilância.

Também serão de responsabilidade do empregador os custos relativos aos equipamentos para o exercício da atividade laboral, os quais deverão estar expressamente contidos, por escrito, quando da contratação. Sendo responsabilidade do empregado o cuidado pelo seu bom manuseio e guarda.

Com relação à saúde e à segurança do empregado, o empregador é responsável pelo amparo, conforme a Diretiva Européia 89/391, assim como as diretivas particulares, legislações nacionais e normas coletivas pertinentes, devendo informá-lo sobre a política empresarial em matéria de saúde e segurança no trabalho. Por sua vez, o teletrabalhador se obriga a aplicar tais políticas corretamente. Importante destacar, que para verificar a correta aplicação dessas normas em matéria de saúde e segurança, o empresário, os representantes dos trabalhadores e/ou as autoridades competentes têm garantido o acesso ao local de 
trabalho, com observância aos limites da legislação e das normas coletivas. Portanto, se o trabalhador remoto labora em seu domicílio, o acesso para fiscalização estará submetido à prévia notificação e consentimento.

O Acordo Marco Europeu não descuida de esclarecer que a organização do tempo de trabalho do teletrabalhador deverá ser administrado pelo próprio e, que sua carga de trabalho e os critérios de resultados deverão ser equivalentes aos dos trabalhadores presenciais.

No mesmo sentido, os teletrabalhadores deverão receber formação adequada e ter as mesmas possibilidades de acesso à formação e ascensão na carreira que os trabalhadores presenciais, estando, igualmente, sujeitos às mesmas regras de avaliação profissional.

Destaca-se a preocupação com o bem estar psicológico do empregado distante, uma vez que o Acordo impõe ao empregador a tomada de medidas para evitar o isolamento do teletrabalhador, devendo o gerar oportunidades para que se encontre regularmente com os demais colegas.

Por fim, é garantido aos teletrabalhadores igualdade de direitos coletivos aplicado aos outros trabalhadores que laboram no ambiente tradicional da empresa. Não sendo possível colocar dificuldades à comunicação dos mesmos com seus representantes. Os teletrabalhadores se sujeitarão às mesmas condições de participação e elegibilidade a que são submetidos outros trabalhadores, em todos os sentidos.

Na Espanha, o Real Decreto Lei 3, de 10 de fevereiro de 2012, atualiza as garantias que são estendidas ao teletrabalhador, no seguinte sentido: conferir uma forma particular de organização do trabalho, que se encaixe perfeitamente no modelo produtivo e econômico perseguido, para promover a flexibilidade dos empregados na organização do trabalho, fomentar e pulverizar as oportunidades de emprego e otimizar a relação entre tempo de trabalho e vida pessoal do trabalhador.

Consoante pré-afirmado, o Acordo Marco Europeu sobre Teletrabalho vem sendo utilizado por vários países da Europa, bem como por entidades de representação econômicas e profissionais, como vértice para o estabelecimento de relações de teletrabalho. Na Espanha, por exemplo, onde algumas convenções coletivas já regulavam o teletrabalho antes mesmo da subscrição do Acordo Marco Europeu, o Acuerdo Interconfederal para la Negociación Colectiva de 2003 REVISTA DO DIREITO UNISC, SANTA CRUZ DO SUL №. 44 | p.107-135 | SET-DEZ 2014 
reconheceu o Marco como documento viabilizador da modernização das empresas, além de mecanismo de conciliação da vida profissional e pessoal para os trabalhadores, que usufruirão de maior autonomia para a realização de suas tarefas particulares e familiares. Igualmente, o Acuerdo Interconfederal para la Negociación Colectiva de 2005 voltou a destacar as características do teletrabalho.

\subsection{Brasil: (in) existência de regulamentação legal}

Muito recentemente, em 15 de dezembro de 2011, foi publicada a lei $12.551^{11}$ ${ }^{12}$, que modificou a redação original ${ }^{13}$ do artigo $6^{\circ}$ da Consolidação das Leis do Trabalho, "para equiparar os efeitos jurídicos da subordinação exercida por meios telemáticos e informatizados à exercida por meios pessoais e diretos"14, visando em verdade tutelar o teletrabalho. No entanto, acredita-se que o legislador ordinário, ao tentar cumprir seu papel, o fez de forma muito aquém à necessária para que se possa falar em efetiva existência e eficácia de uma tutela ao teletrabalhador no Brasil, já que as dúvidas sobre a nova forma de trabalho não foram minimante solucionadas.

A atual legislação deixa lacunas, que, por óbvio, devem ser preenchidas, até mesmo sobre os aspectos constitucionais da relação laboral. Já que, quando não sanadas, tais brechas abrem margem de insegurança jurídica aos empregados e empregadores em seu relacionamento.

\footnotetext{
${ }_{11}$ A Lei $\mathrm{n}^{\circ}$. 12.551/2011 teve origem no Projeto de Lei $\mathrm{n}^{\circ}$. 3.129/2004, de autoria do Deputado Eduardo Valverde, pertencente ao Partido dos Trabalhadores - PT de Rondônia, apresentado ao Congresso Nacional, aonde recebeu parecer favorável dos integrantes da Câmara dos Deputados, sendo, posteriormente, remetido ao Senado Federal, sob o no. 102/2007, para apreciação. O Projeto de Lei no. 102/2007 teve por finalidade equiparar os efeitos jurídicos da subordinação exercida por meios telemáticos e informatizados à exercida por meios pessoais e diretos, ou seja, abrangeria, expressamente, os teletrabalhadores. Ao justificar sua iniciativa, o autor da proposição afirma que a evolução tecnológica e as mutações do trabalho exigem permanentes transformações da ordem jurídica com $o$ intuito de apreender a realidade variável. $O$ tradicional comando direto entre 0 empregador e o empregado, hoje, cede lugar ao comando à distância, mediante o uso de meios telemáticos em que o empregado sequer sabe quem é o emissor da ordem de comando e controle.

12 Justificativa contida no Parecer, de relatoria do Senador Cristovam Buarque. Disponível em: <http://www.senado.gov.br/atividade/materia/getPDF.asp?t=22949>. Acesso em: 30 jun. 2010.

13 Art. 60 - Não se distingue entre o trabalho realizado no estabelecimento do empregador e 0 executado no domicílio do empregado, desde que esteja caracterizada a relação de emprego. Parágrafo Único: Os meios telemáticos e informatizados de comando, controle e supervisão se equiparam, para fins de subordinação jurídica, aos meios pessoais e diretos de comando, controle e supervisão do trabalho alheio.

${ }^{14}$ Texto retirado do preâmbulo da lei 12.551/2011.
} 
Ou seja, a nova lei nada fez além de incluir alguns substantivos (trabalho realizado a distância, meios telemáticos e informatizados de comando, controle e supervisão) ao texto de 1943. Em que nada o modificaram em relação à proteção que anteriormente se podia estender ao teletrabalhador por meio de interpretação e subsunção dos fatos à lei, não modificando a problemática existente e o que já se vinha fazendo através da jurisprudência.

Nesse sentido, afora compreender que seriam estes trabalhadores empregados, restam ainda algumas dúvidas, como por exemplo: estariam eles subordinados a qual categoria sindical? Como controlar o trabalho desses trabalhadores, alcançando-lhes direitos fundamentais sem, contudo, ferir sua intimidade, vida privada e mesmo a honra? O controle da higiene e segurança desses trabalhadores fica a cargo de quem, já que o trabalho à distância, através dos meios telemáticos, pode ser prestado de/em qualquer lugar? Será possível controlar de forma eletrônica a duração do trabalho, tendo em vista o teor da Portaria 1510/2008? Esses questionamentos, bem como outros tantos ainda restam pulsantes no Brasil, apesar da pré-citada lei.

No entanto, verifica-se que ainda permanece em análise o Projeto Lei no 4505/2008, de autoria do Deputado Luiz Paulo Vellozo Lucas, o qual pretende regulamentar de forma minuciosa o trabalho a distância, além de conceituar e disciplinar as relações de teletrabalho. O projeto, entretanto, também não é dos mais felizes, quer por sua incompreensão do próprio instituto do teletrabalho, quer por problemas de técnica legislativa ou até mesmo, em alguns momentos, de questionável constitucionalidade de seus termos. Segundo o Projeto Lei, para que o teletrabalho seja caracterizado, o empregado deve ocupar mais de $40 \%$ de seu tempo de trabalho fora dos locais regulares, como a sede da empresa, por exemplo. Ainda segundo o Projeto, o teletrabalho deverá servir de instrumento para a criação de empregos, inclusive de vagas destinadas a pessoas com capacidade física reduzida. Impende destacar, que ao projeto agregou-se emenda, apresentada por sua relatora, a Deputada Manoela D’Ávila, contribuindo significativamente para a inclusão das pessoas com deficiência no âmbito do trabalho através da inclusão de previsão de reserva a estas de $20 \%$ dos postos de trabalho na modalidade de teletrabalho, o que permitiria à pessoa com deficiência interagir com a sociedade e 
impor-se, por meio do ciberespaço, em condição de igualdade com os demais indivíduos.

A partir das premissas apontadas, observa-se que apesar de haver iniciativas e projetos de leis, não existe real e comprometido empenho do parlamento brasileiro no sentido de regulamentar a matéria, com eficiência, imediatismo, eficácia e de forma sistemática. Quanto mais tendo por paradigma o Acordo Marco Europeu e a experiência de alguns países, naquele contexto, que já regraram o tema.

A Constituição Federal de 1988, desde o seu preâmbulo até a regulamentação da economia nacional, impõe a dignidade da pessoa humana, nas suas diversas dimensões, como princípio norteador. Ao longo do texto Constitucional é possível aferir a valorização social do trabalho, uma vez que é por meio deste que os indivíduos obtêm boa parte do necessário à sua subsistência; já que o trabalho pressupõe o assegurar de uma vida digna, conduzindo, com mais facilidade, à construção de uma sociedade justa e fraterna.

Sob esse aspecto, se pode dizer que a modificação introduzida na Consolidação das Leis do Trabalho responde parcialmente à necessidade e expectativa de regulamentação do teletrabalho. Dir-se-ia até, que responde deficitariamente ou que nada responde, eis que, como pré-dito, em nada altera o que a jurisprudência já vinha fazendo: singelamente equipara o teletrabalho ao trabalho presencial. A regulamentação das minúcias, que se esperava dela, ainda não veio.

Portanto, entende-se que o teletrabalho não se encontra regulamentado de forma segura e eficiente no ordenamento jurídico laboral brasileiro. Não tendo cumprido, o legislador ordinário, seu objetivo de alcançar a efetivação dos direitos fundamentais individuais e sociais mínimos aos teletrabalhadores.

O sistema jurídico nacional ainda não está preparado para lidar com a questão do teletrabalho a partir de normas de tipo aberto.

No mais, pode-se dizer, que, imediatamente, em complementação às lacunas da legislação e dadas as especificidades do teletrabalho, o instrumento mais eficaz na realidade brasileira é, sem dúvida, a negociação coletiva. À medida que forem sendo implementadas as negociações, conforme as necessidades surgidas nas categorias, que potencialmente abriguem teletrabalhadores, certamente surgirão novos mecanismos para solucionar ou minimizar as questões controvertidas. Um 
bom exemplo de complementação da legislação sobre teletrabalho via negociação coletiva é a Itália, que rege a matéria pelo chamado Acordo Interconfederativo, de 9 de Junho de $2004^{15}$, e que também tem como norte o Acordo Marco Europeu.

\subsection{Uso da negociação coletiva como forma de regulamentar o teletrabalho}

O artigo $8^{\circ}$ da Constituição Federal de 1988 versa, especificamente, sobre o sistema sindical brasileiro. $\mathrm{O}$ artigo $7^{\circ}$, inciso $\mathrm{XXVI}$, do mesmo diploma legal, por sua vez, reconhece a eficácia das convenções e os acordos coletivos de trabalho.

Assim sendo, a atuação do trabalhador por meio do teletrabalho, por si só, é, em princípio, elemento desagregador à idéia de coletividade, uma vez que este tipo de trabalhador, pela falta do presenteísmo, está afastado das reivindicações coletivas e das ações sindicais.

A comunicação via meios telemáticos está cada vez mais inserida no meio laboral e social, face uso das novas tecnologias, mas, indubitavelmente, não substitui, e quiçá nunca substituirá, o contato pessoal (STÜRMER, 2011).

A preferência (ou acomodação?) ao contato virtual faz parte da pósmodernidade ou, como diria Baumann (2011), da "modernidade líquida". As novas gerações estão crescendo inseridas no mundo eletrônico, no vivendo no "ciber". Afora o convívio em redes sociais virtuais (para o que há estudos acerca da "humanidade" deste tipo de relacionamento), pode-se dizer que o padrão individualista é regra e, que, infelizmente, está reduzido o espaço para noções de solidariedade, colaboração e participação coletiva na vida social.

Observa-se, pois, que a idéia central, de interesse coletivo, do sistema sindical tem e terá enormes dificuldades para adaptação à chamada Sociedade da Informação e/ou Sociedade Líquida. A atividade e a dinâmica sindical brasileiras perderão função e se verão obstaculizadas, sem a superação da ideia de que o local de trabalho como algo fixo, geográfico e palpável. É preciso passar a estudar, conhecer e admitir o ciberespaço nas relações laborais, em especial pela possibilidade do teletrabalho transfronteiriço (STÜRMER, 2011), mas também para fins de representação sindical, equiparação laboral e outros temas.

\footnotetext{
${ }_{15}$ Vide texto completo em: <http://www.uil.it/pol_contrattuali/accordo_telelavoro2004.pdf>
} 
Consequentemente, os meios eletrônicos, especialmente os correios eletrônicos e a internet (por meio dos blogs e fóruns de debate), são e serão ferramentas para que o sindicato contate com os representados e até mesmo para seus movimentos coletivos ${ }^{16}$.

No Brasil, a regulamentação do teletrabalho ainda encontra-se em fase de discussão, uma vez que a alteração do artigo 6ำ da Consolidação das Leis do Trabalho, pode ser entendida apenas como primeiro movimento de uma série de atos necessários. Realizado no intuito de equiparar os efeitos jurídicos da subordinação como elemento prima facie do reconhecimento de relação de emprego àqueles trabalhadores que exercem seu trabalho por meios telemáticos e informatizados aos trabalhadores presenciais, sujeitos ao controle direto, tradicional e pessoal. Como pré-dito, isto não satisfaz, porque não alcança aos envolvidos a segurança jurídica. A regulamentação complementar, através de novas alterações da Consolidação das Leis do Trabalho terá tramitação burocrática e lenta ${ }^{17}$, por isso a sugestão às entidades sindicais, para que ocupem seu espaço.

A regulação do teletrabalho por meio de normas coletivas é muito diversa e díspar na União Européia. Alguns países como Portugal, Holanda, Luxemburgo, Grécia, Bélgica e Finlândia, não regulam o teletrabalho por meio de normas coletivas (JIMÉNEZ, 2007). Em outros países, como França, Alemanha, Irlanda e Reino Unido, em termos gerais, se pode dizer que o teletrabalho não está regulado mediante convenção coletiva, contudo algumas empresas proporcionam certa regulamentação por meio de acordos pactuados entre empregadores e empregados (JIMÉNEZ, 2007). Há apenas, um pequeno número de países, que têm desenvolvido e regulado plenamente o teletrabalho por meio de normas coletivas, podendo-se citar Suécia, Itália e Dinamarca (JIMÉNEZ, 2007).

É nítido que a negociação coletiva pode, e quiçá, em termos de Brasil, deva, ser o meio mais ágil e hábil para que seja estabelecido o regramento sobre a matéria. Neste contexto, sugere-se que cada categoria profissional agregue ao seu instrumento coletivo normas para o teletrabalho, na medida em que o teletrabalhador é trabalhador de diversas atividades e categorias, o que, salvo melhor juízo, afasta a

\footnotetext{
${ }^{16}$ Neste sentido, a greve virtual dos trabalhadores da IBM no second life é boa experiência. Vide sobre 0 fato: <http://www.estadao.com.br/noticias/tecnologia,funcionarios-da-ibm-protestam-nosecond-life, $57508,0$. htm>

${ }^{17}$ Trata-se de mecanismo de contenção próprio ao processo legislativo.
} 
idéia de criação de sindicato próprio para teletrabalhadores (via reconhecimento de categoria profissional diferenciada).

As relações coletivas sempre existirão e devem permanecer existindo, a despeito da forma como irão buscar satisfazer os objetivos dos que compõem a coletividade. O sindicato de hoje não é o sindicato de ontem e nem será o de amanhã. O teletrabalho, por fim, é ferramenta e meio de trabalho, cabendo às entidades sindicais efetivamente integrarem esse meio virtual em que os trabalhadores estão inseridos.

\section{CONCLUSÃO}

A revolução dos meios de comunicação levou o trabalhador a prestar serviços em sua residência ou em quais quer outros locais que não a sede da empresa. É o fenômeno do teletrabalho, realidade laboral que emerge no mundo moderno.

Ao lado do trabalho tradicional e presencial, em que o empregado fica direta e pessoalmente subordinado ao empregador, surgiram outras prestações de serviço, alheias até mesmo ao ambiente da empresa, permitindo que as atividades laborais sejam desenvolvidas de forma mais flexível, trazendo vantagens tanto para o prestador do serviço, que não precisa se deslocar até a empresa, quanto ao próprio tomador/empregador, que se desonera de várias despesas, notoriamente estruturais.

Sendo assim, considera-se que o teletrabalho pode se configurar como elemento de importante transformação no mundo do trabalho. Porém, este tipo de trabalho tem de ser amparado pela legislação laboral brasileira, que não poderá ignorar as peculiaridades que ele apresenta. Exemplos de boa técnica legislativa estão na Europa, guiados pelo Marco Europeu, que podem servir de paradigma ou até mesmo, de fontes de aplicação subsidiária (forte no que dispõe o artigo $8^{\circ}$ da CLT).

Imagina-se, diante dos quadros comparados avaliados, da norma aberta de que dispõe hoje o Brasil e da cultura legislativa brasileira (que está acostumada ao minuciamento das matérias), ser possível agregar maior segurança nas relações de teletrabalho caso as categorias (profissional e econômica) estiverem guiadas e 
amparadas em suas relações por normas produzidas em negociações coletivas, vez que cogentes, pontuais, dinâmicas e flexíveis.

Espera-se com isto, no que toca ao teletrabalho, a obtenção de maior grau de segurança jurídica, pois o escopo do Direito do Trabalho é a valorização do trabalho, como propulsor da economia e do crescimento pessoal do trabalhador, o que se dará através da regência eficaz e justa de suas relações subordinadas de prestação laboral.

\section{Referências}

ANDRADE, Pollyanna Vasconcelos Correia Lima de. Teletrabalho no ordenamento jurídico brasileiro. Revista do Tribunal Regional do Trabalho da 13a Região: João Pessoa, v. 15, n.1, 2007. p.284-303.

BAUMANN, Zignunt. O mal-estar de pós-modernidade. (trad. Maura Gama e Cláudia Martinelli Gama). Rio de Janeiro: Zahar, 1998.

BRASIL. Sociedade da informação no Brasil: livro verde. Org. Tadao Takahashi. Brasília: Ministério da Ciência e Tecnologia, 2000.

CASTELLS, Manuel. A sociedade em rede: a era da informação: economia, sociedade e cultura. vol.1. São Paulo: Ed. Paz e Terra, 2000.

COCCO, Giuseppe. A nova qualidade do trabalho na era da informação. In: Informação e globalização na era do conhecimento. Helena M. M. Lastre e Sarita Albagli (Orgs.). Rio de Janeiro: Campus, 1999.

COCCO, Giuseppe. Trabalho e cidadania - Produção e direitos na era da globalização. São Paulo: Ed. Cortez, 2000.

DARCANCHY, Mara Vidigal. Teletrabalho para pessoas portadoras de necessidades especiais. São Paulo: LTr, 2006.

DE MASI, Domenico. O futuro do trabalho. Brasília: Ed. da UNB, 1999.

DE MASI, Domenico. O futuro do trabalho. Fadiga e Ócio na Sociedade PósIndustrial. Rio de Janeiro: José Olympio. 1999.

FINCATO, Denise Pires. Teletrabalho: uma análise juslaboral. Revista Justiça do Trabalho, n. 236, ago. 2003.

FINCATO, Denise Pires. Teletrabalho: uma análise juslaboral. In: Questões controvertidas de Direito do Trabalho e outros estudos. STURMER, G. (org). Porto Alegre: do Advogado, 2006. 
FINCATO, Denise Pires. Teletrabalho: aproximações epistemológicas. In: Revista Magister de Direito Empresarial, Concorrencial e do Consumidor. Porto Alegre: Magister, abr-maio, 2009.

FINCATO, Denise Pires. Teletrabalho. Sítio do $4^{\circ}$ Congresso lberoamericano de Teletrabalho e Teleatividades. Disponível em http://www.citbrasil2011.com.br. Acessado em 31/10/2011.

FRANCO FILHO, Georgenor de Sousa. Globalização e desemprego: mudanças nas relações de trabalho. São Paulo: LTr, 1998.

FRIEDMAN, Georges. O FUTURO DO TRABALHO HUMANO. 2 ed. Lisboa: Moraes. 1981.

FRIEDMAN, Thomas L. O mundo é plano - o mundo globalizado no século XXI. 3.ed. Rio de Janeiro: Objetiva, 2009.

JARDIM, Carla Carrara da Silva. O teletrabalho e suas atuais modalidades. São Paulo: LTR, 2004.

JIMÉNEZ, Carmen Algar. Teletrabajo. In. El Derecho Laboral ante el reto de las Nuevas Tecnologias. Madri: Difusión Jurídica y Temas de Actualidade, S.A., 2007.

MAÑAS, Christian Marcello. A externalização da atividade produtiva: o impacto do teletrabalho na nova ordem socioeconômica. Revista da Faculdade de Direito da UFPR. [s/l], v. 39, 2003.

MELO FILHO, Hugo Cavalcanti. Impulsos Tecnológicos e Precarização do Trabalho. In: Revista da Amatra VI, Pernambuco, ano IV, no 11, p. 05-08, 2000.

NILLES, Jack M. Fazendo do Teletrabalho uma realidade: um guia para telegerentes e teletrabalhadores. São Paulo: Futura, 1997.

PADILLA, Antonio. Teletrabajo Dirección y Organización. Madrid: Ed. RA-MA, 1998.

PEDREIRA, Pinho. O Teletrabalho. Legislação do Trabalho, n. 05, v. 64, p.583-87, 2000.

PEDREIRA, José Pinho. O teletrabalho. Revista LTr, São Paulo, v. 64, n. 5, maio 2000.

ROCHA, Marcelo Oliveira. Direito do Trabalho e Internet. São Paulo: Livraria e Editora Universitária de Direito, 2004.

SAKUDA, Luiz Ojima. Teletrabalho: desafios e perspectivas. Orientador Flavio de Carvalho Vasconcelos. Dissertação (Mestrado). Escola de Administração de Empresas de São Paulo, Fundação Getulio Vargas. São Paulo, 2001. 
SANTOS, Boaventura de Sousa. A globalização e as ciências sociais. São Paulo: Cortez, 2005.

SILVA, Frederico Silveira e. O teletrabalho como novo meio de laborar e sua compatibilidade com o ordenamento jurídico. Revista CEJ, Brasília DF, n. 27, p. 102109, 2004.

STÜRMER, Gilberto. Relações Coletivas e Teletrabalho. In: IV Congresso ÍberoAmericano de Teletrabalho e Teleatividades, 2011, Porto Alegre. Relações Coletivas e Teletrabalho. Porto Alegre : Magister, 2011. v. 1. p. 66-75.

TOFFLER, Alvin. Powershift: as mudanças de poder. 4 ed. Rio de Janeiro: Record, 1995.

WINTER, Vera Regina Loureiro. Teletrabalho: uma forma alternativa de emprego. São Paulo: LTr, 2005. 